\title{
DITORIAL
}

\section{Language communication and media from the East}

This special issue of CALIGRAMA is devoted to building ties, or a first acquaintance, between researchers of the East and West, who are concerned, above all, with language and communication and the effects of globalization.

By introducing Brazilian researchers to the research of colleagues in China, the Philippines, Japan, Slovenia, Turkey, Kuwait, Australia and Norway, CALIGRAMA was designed as a means of exchange that lead to the discovery of commonalities.

This issue began with our participation in the Second International Conference on Multicultural Discourses, held in April of this year, at the Institute of Discourse \& Cultural Studies of Zhejiang University in Hangzhou, a city that was the seventh capital of China.

This proposal that, in one way or another, guided the selection of the works for the conference had in mind a discussion of alternative theories that are not based on Western thinking. Despite the unexpected nature of the responses, the serious issues that emerged were unique, since, despite arising from the same process-international communication networks (media networks)-the effects are not the same. They differ depending on geographic location.

In this way, the realization that the English language and with it the Latin alphabet establish a hegemony, perhaps never before seen in the history of man, create a controversial space which cannot be defined by struggle or dispute alone.

The sciences of language suggest that the edges of this space go beyond religious, ethnic, cultural and geopolitical differences and establish the way in which each detail of a language (or spoken and written languages) is deep and vividly embodied in the different representations of the constantly changing contemporary world. We can expect exchange, interpenetration and a vast network of commonalities and differences.

The articles in this special issue of CALIGRAMA are offered as a map of these similarities and variations.

J.O. Zulueta, MA in sociology from the University of Manila in the Philippines and PhD candidate at the University of Hitotsubashi in Tokyo, in the work "I speak chinese, but..." Code-Switching and Identity Construction among Chinese- 
Filipino Youth, by studying the adaptation of Chinese-Filipino youth to Philippine society, this paper illustrates clearly these exchanges and interpenetrations, in an effort to build an ethnic identity.

K. Juffermans, another PhD candidate at the University of Hong Kong, takes a look at basic level English education in public schools in rural Gambia and, arguing against linguistic imperialism, puts forth multilingual communication as a way of introducing the local language into the school curriculum. The article, If I don't learn English, I am going to suffer: Gâmbia lower basic school children's voice in the medium of instruction debate, is part of a broader ethnographic study and lays out in detail the stages of the study.

In the Footsteps of Apostles -The role of English teachers in the age of EIL, is the work of Katsuhiro Ohashi, a professor of linguistics, semiotics and English at Ritsumeikan Asia Pacific University in Japan, discusses a current issue, the dominance of English, in an unusual way. By taking issue with the Tower of Babel, which represents the curse of multilingualism and the Acts of the Apostles (Chapter 2) in which the same multilingualism is described as a gift from God, he makes a distinction between the English language itself, whose planetary dominance means bilingualism, that is, a pre-Babel situation, and English which is spoken in a transformed manner, according to the region to which it is adapted, resulting in an international language (EIL), or in other words, multilingualism. The thesis is supported intelligently by the basic concepts of F. de Saussure: language and speech.

Globalization, as such, is addressed from different perspectives: Culture in the Context of Globalization: a Sociological Interpretation, by Xia Guang, an associate professor at the Macao Polytechnic Institute School of Business, and $\mathrm{PhD}$ from the University of Toronto, examines cultural phenomena such as ethnocentrism and cultural relativism and seeks a theoretical construction of a possible mechanism of coexistence and symbiosis between different cultures. Feng Hui, of the College of Social Sciences and Foreign Languages at Tianjin University, in the article The Changing Language Ideology and Linguistic Market in the Globalization of China, explores the uniqueness of the process of globalization and China and highlights a change in the contraception of language, formerly considered an instrument and, today, thought of as capital whose use will result in benefits for society. Keitaro Morita, of the Department of Social Design Studies at Rikkyo University, Tokyo, uses the theory of materialistic ecofeminism as a way to analyze global warming. The text For a Better Environmental Communication: A Materialist Ecofeminist Analysis of Global Warming by a Male Japanese Ecofeminist offers an intriguing reading of the issue.

In another paper, Professor Cao Shunqing, Dean of the College of Literature and Journalism, at Sichuan University in China, highlights the basic principles of Chinese literary discourse, in an effort to systematize the dialogue between heterogeneous literary theories. The article The Discourse of Chinese Literary Theory and the Dialogue between Western Literary Theory and Chinese Literary Theory is the result of a long process of research.

Still on the topic of literature, Qiang Huang, of Tianjin Foreign Studies University in China, sheds light on the building of identities related to ethnicity, displacement and marginalization, by analyzing the novel The World Waiting to be Made (1994) by award winning writer Simone Lazaroo, who was born in Singapore and has lived in Australia since 1963.

Journalism is the topic of study by Karmen Erjavec, an associate professor of the Faculty of Social Sciences at the University of Ljubljana, Slovenia and Zala Volcic, a lecturer at the School in Journalism and Communication at the University of Queensland, Australia. The authors of the article Croatian Journalists' narratives 
on Croatian war crimes in Bosnia-Herzegovina defend the thesis that, during the civil war in Yugoslavia, the media played an important role in creating the Other ethnic group (the enemy). Interviews carried out with Croatian journalists and analysis of the journalistic narratives enabled them to establish clarifying relationships between the reports and specific ideologies. The researchers demonstrated that the appropriation of discourse like the war on terrorism, the war in Iraq, European and neoliberal discourse all operate in the building of narratives and justify a nationalistic ideology-Great Croatia-as well as serving to promote war crimes against Bosnian Muslims.

Hakan Ergül is a professor of cultural studies, media ethnography and journalism at the Faculty of Communication of Anadolu University in Turkey. He earned his PhD from the Graduate School of International Cultural Studies at Tohoku University in Japan. H. Ergül addresses a current topic: the entry of Turkey into the European Union by exploring the deep fissures that 50 years of discussion of the problem by the Islamic media have caused in the discursive construction of Europe. The article Destination Europe: The Representation(s) of Turkey EU in Islamic Newspapers an interesting analysis carried out on four established newspapers shows that, even supported by political, cultural and ideological references of the Islamic cause, the dominant discourse by which they respond to Europe and the political strategy of the conservative party (AKP) show significant changes in relation to the possibility of entering the European Union.

The evasive strategies used in press conferences given by government spokespersons, in this case, the spokesman for the Foreign Affairs Ministry of China and that of the State Department of the United States, is an issue addressed by Dou Weilin, a professor of the School of International Studies, University of International Business and Economy, Beijing, and his colleague Zhang Xiaoying. The concepts and work method that led them to identify the different forms of evasion prove fascinating reading, Cross-cultural Pragmatic Analysis of Evasion Strategy at Chinese and American Press Conferences-with Special Reference to the North Korean Nuclear Issue.

Remodeling in Kuwaiti Newspaper Commentary Titles is a contribution by Mohammed Farghal, PhD, professor of linguistics and translation of the Department of English, Kuwait University, with his co-author Mashael Al-Hamly, professor of applied linguistics, at the same university, supported by a bibliography of familiar Western researchers and analysis of material extracted from two Kuwaiti newspapers. The article presents a consistent definition of remodeling as the discursive mechanism, which allows clarification of the connections between the linguistic resources employed as well as the questioning of ideological interferences in the choice between the remodeled title and the original.

Katherine Goodnow and Wu Heng, of the University of Bergen, Norway, question the traditional historical view of museums: Which multicultural discourses exist in contemporary Museum exhibitions and which are silenced? What forms of ethnocentrism exist and how are they represented in the language and in the images used by museums? What narratives and which images are favored and which are omitted?

The search for an answer and the hope that museums are on track in their transformation into places that enable intercultural dialogue, the text uses exhibitions focused on Chinese migration in the museums of Australia, New Zealand, the United States, Panama and several European countries.

The editors of CALIGRAMA hope that this first international incursion yields fruit and results in the building of an extensive network of communications between intellectuals committed to contemporary artmaking. 